\title{
RECOVERY OF ITACONIC ACID BY ELECTRODIALYSIS
}

\author{
VERONIKA VARGA ${ }^{1}$, KATALIN BÉLAFI-BAKÓ ${ }^{1}$, DÁVID VOZIK ${ }^{1}$, AND NÁNDOR NeMESTÓthy *1 \\ ${ }^{1}$ Research Institute of Bioengineering, Membrane Technology and Energetics, University of Pannonia, \\ Egyetem u. 10, Veszprém, 8200, HUNGARY
}

\begin{abstract}
Itaconic acid is an organic acid produced mainly for non-food purposes. It can be manufactured by biotechnological synthesis using various strains which results in the salt form of the acid. In this work, the separation of sodium itaconate by electrodialysis was studied. Homopolar cation- and anion-selective membranes were applied and the module was operated under a constant voltage. The transport of the acid was followed by on-line ultraviolet and visible absorption spectroscopy, where the detector was installed in the system. The experiments with models of aqueous solutions confirmed that the technique is suitable for the effective recovery of itaconic acid.
\end{abstract}

Keywords: ultraviolet and visible absorption spectroscopy, on-line detection, monopolar membranes

\section{Introduction}

Itaconic acid was discovered by Baup in 1837 as the coproduct resulting from the degradation of citric acid [1]. Itaconic acid (2-methylene,1,4-butanedioic acid) is an unsaturated dicarboxylic acid, a rather reactive compound due to its conjugated double bond and two carboxyl groups. Therefore, it can easily participate in polymerisation reactions.

Itaconic acid - unlike citric acid - is applied exclusively for non-food purposes [2]. It is used mainly in the production of synthetic fibres and ion-exchange resins as well as in the pulp and paper industry.

Itaconic acid can be synthesized biotechnologically. Kinoshita was first to describe the process in 1932 when it was isolated from the broth of Aspergillus itaconicus [3]. Later a similar strain, Aspergillus terreus, was found to produce itaconic acid. Other microbes suitable for the fermentation of itaconic acid are listed in Table 1.

The main problem with downstream processing is that several similar organic acids are present in the broth, thus, recovery of itaconic acid is difficult. Separation of itaconic acid can be conducted by filtration with the aid of activated carbon and crystallisation (consecutive steps) or adsorption by strong anion-exchange resins, like Purolite A-500 P or PFA-300 [10]. The efficiency of the separation depends mainly on the temperature, $\mathrm{pH}$ and concentration.

An application of electrodialysis (ED) as a membrane process is the separation of organic acids [11-14]. Malic acid and galacturonic acid amongst others can be separated by ED using monopolar and bipolar membranes by

\footnotetext{
*Correspondence: nemesn@almos.uni-pannon.hu
}

Table 1: Biotechnological synthesis of itaconic acid

\begin{tabular}{ll}
\hline Strain & Reference \\
\hline $\begin{array}{l}\text { Aspergillus } \\
\text { itaconicus }\end{array}$ & Kinoshita et al. (1932) [3] \\
$\begin{array}{l}\text { Ustilago } \\
\text { maydis }\end{array}$ & Steiger et al. (2013) [4] \\
$\begin{array}{l}\text { Pseudozyma } \\
\text { antarctica }\end{array}$ & Levinson et al. (2006) [5] \\
$\begin{array}{l}\text { Yarrowia } \\
\text { lipolytica }\end{array}$ & Kuenz et al. (2018) [6] \\
$\begin{array}{l}\text { Synechocystis } \\
\text { cyanobacteria }\end{array}$ & Heidorn et al. (2011) [7] \\
$\begin{array}{l}\text { Aspergillus } \\
\text { terreus }\end{array}$ & Karaffa et al. (2015) [8] \\
\hline
\end{tabular}

implementing batch and continuous modes of operation.

The majority of these acids are produced as a salt, thus, the aim of the separation by ED is to transport the organic acid through the anion-selective membrane, while the cation should pass through the cation-selective membrane. The other neutral components remain in the feed solution. Usually the mobility of the acid is sufficient for effective transport, hence both the acid and cation can be recovered by ED.

The aim of this paper was to study the possibility of applying ED for the recovery of sodium itaconate.

\section{Experimental}

Itaconic acid, sodium sulphate, sulphuric acid, sodium hydroxide and all the other chemicals used were of an- 
Table 2: Features of the membranes

\begin{tabular}{lll}
\hline Feature & Fumasep FAA & Fumasep FKS \\
\hline $\begin{array}{l}\text { selectivity } \\
\text { electrical }\end{array}$ & $>92 \%$ & $>96 \%$ \\
resistance & $<2 \Omega \mathrm{cm}^{2}$ & $<8 \Omega \mathrm{cm}^{2}$ \\
pH stability & in acidic media & $5-13$ \\
$\begin{array}{l}\text { thickness } \\
\begin{array}{l}\text { ion-exchange } \\
\text { capacity }\end{array}\end{array}$ & $>13-0.15 \mathrm{~mm}$ & $0.11-0.13 \mathrm{~mm}$ \\
conductivity & $>8 \mathrm{mS} / \mathrm{cm}$ & $>1.0 \mathrm{meq} / \mathrm{g}$ \\
\hline
\end{tabular}

alytical grade and purchased from Sigma-Aldrich. The anion- and cation-selective membranes were Fumasep FAA and FKS membranes, respectively. The main features of the membranes are summarized in Table 2. The membranes were activated by sodium chloride and sulphuric acid before usage.

For analytical purposes a Young Lin Instrument Co., Ltd. (YL9100-type) high-performance liquid chromatography (HPLC) system (including a YL9109 vacuum degasser, YL9110 quaternary pump and YL9150 automatic sample dispenser) was used to determine the concentration of itaconic acid with a Hamilton HPLC column (15 $\mathrm{cm}$ in length, $4.6 \mathrm{~mm}$ inner diameter, $5 \mu \mathrm{m}$ particle size) and a YL9120 UV/Vis detector.

The Luff-Schoorl method was used to determine the glucose concentration which is based on the reduction of cupric $(\mathrm{Cu}(\mathrm{II}))$ cations in a boiling alkaline solution of cuprous $(\mathrm{Cu}(\mathrm{I}))$ oxide [15]. The surplus of $\mathrm{Cu}(\mathrm{II})$ was measured by iodometry using a titration with sodium thiosulfate.

The conductivity of the solutions was measured by a Radelkis OK-102/1 conductivity meter equipped with a Radelkis OK-9023 bell electrode using a cell constant of $0.7 \mathrm{~cm}^{-1}$. Data concerning the voltage and current were measured by a National Instruments USB-600866009 device. All the experimental data were collected online using LabVIEW software.

An electrodialysis module was constructed from 2 anion- and 2 cation-selective membranes using spacers between them. The electrode solution was an aqueous solution of sodium sulphate.

Electrodialysis measurements were conducted using diluted (aqueous) model solutions of sodium itaconate and sodium itaconate mixed with glucose. The module was operated under a constant voltage.

\section{Results}

In this project, the final aim was to connect the ED device to the fermentation of itaconic acid in order to set up an integrated system. For this purpose, firstly the operation of ED was investigated by using model solutions of sodium itaconate and a simple ED device with monopolar

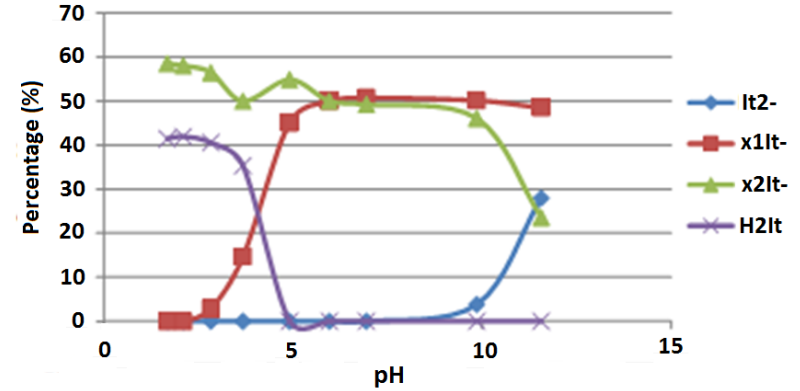

Figure 1: Percentages of the four distinct forms of itaconic acid.

ion-exchange membranes. The transport of the itaconic acid through the anion-selective membranes was the focus of the study

To follow the process, it was important to determine the exact concentration of itaconic acid. If the acid is the only compound in the solution, measuring the conductivity is a simple method for detection. However, if any other charged compound is present, it will disturb such measurements. In this case, HPLC is suggested for the analysis [9].

Itaconic acid is a dicarboxylic acid (consisting of three different ionic forms) and its dissociated forms and ionic strengths vary according to the $\mathrm{pH}$. Thus, four distinct peaks over different retention times can be detected in HPLC chromatograms. The percentages of the four distinct forms as a function of $\mathrm{pH}$ were determined and are presented in Fig. 1.

Since it is quite difficult to measure the actual concentration of itaconic acid, another method was chosen. Itaconic acid has a UV absorption maximum at $243 \mathrm{~nm}$ which can be used for detection. This method seemed sufficiently sensitive for our purposes.

In our work, a loop was constructed from the solution (recirculated in the ED module) to the UV detector. Thus, online detection was applied to follow the concentration

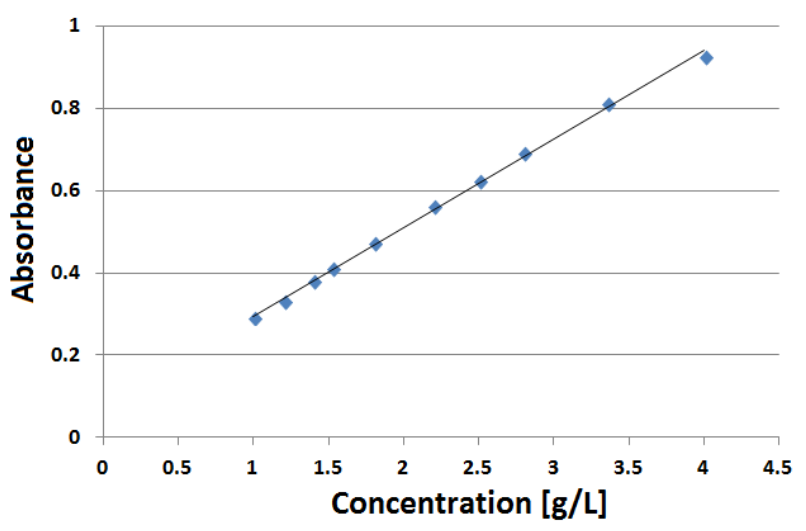

Figure 2: Calibration curve for the determination of itaconic acid concentration by UV detection 


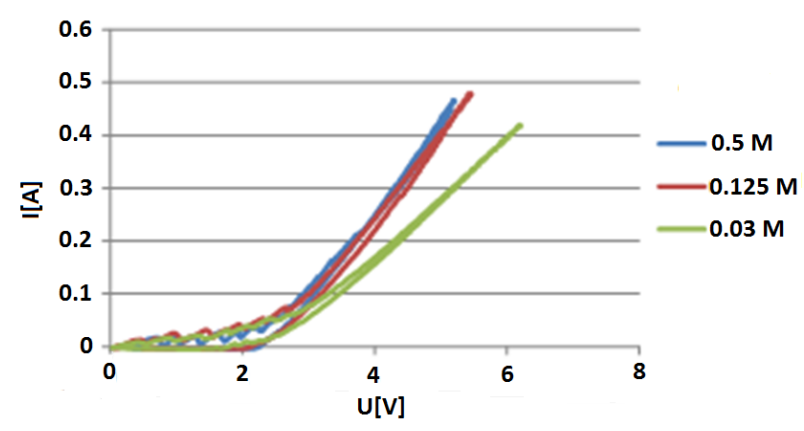

Figure 3: Polarization curves

of itaconic acid as a function of operating time. Firstly, a calibration curve was recorded (Fig. 2) over the concentration range of itaconic acid that was planned to be used. The data measured by the online UV system were checked by HPLC.

To test the ED module, polarization curves were taken using a potentiostat by applying a range of voltages from 0 to $10 \mathrm{~V}$ (Fig. 3). The current data were recorded as a function of the voltage data. The measurements were repeated in various electrode solutions.

It seems that beyond a sodium sulphate concentration of $0.125 \mathrm{M}$, the ED operated properly.

Experiments were conducted in the ED module by using aqueous model solutions of itaconic acid (with an initial concentration of 3-3 g/l). The electrode solution was a $0.16 \mathrm{M} \mathrm{Na}_{2} \mathrm{SO}_{4}$ solution. The experiments were conducted under a constant voltage $(10 \mathrm{~V})$ and the current intensity varied between 0.11 and $0.15 \mathrm{~A}$.

Subsequently, the conductivity in the diluate solution was measured. The concentration of the acid decreased gradually to half its initial value after an operating time of 70 mins as can be seen in Fig. 4. This means that itaconic acid was able to pass through the anion-selective membrane, while sodium ions were able to diffuse across the cation-selective membrane. Therefore, the measurements confirmed that the mobility of this acid is sufficient to separate it by ED.

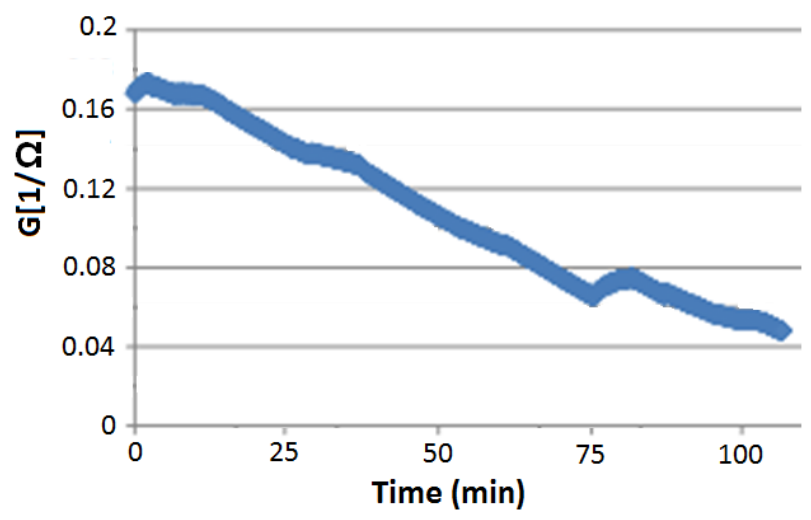

Figure 4: Conductivity data of the diluate of ED

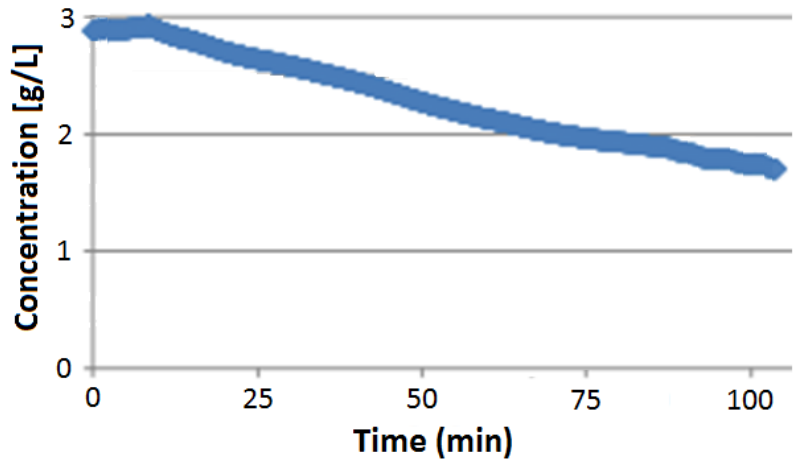

Figure 5: Concentration of itaconic acid in the diluate solution

In the next series of experiments, glucose was added to the acid $(4 \mathrm{~g} / \mathrm{L})$ to investigate whether the ED module was able to separate the two compounds. The concentration of itaconic acid in the diluate was followed online by the UV detector installed in the loop. The concentration of the glucose was determined by the Luff-Schoorl method.

The concentration of the acid decreased from 3.0 to $1.5 \mathrm{~g} / \mathrm{L}$ during the experiment (Fig. 5), while the glucose concentration was monitored in all three streams. In the diluate (originally feed) solution, a slight decrease in glucose concentration was observed (to $3.52 \mathrm{~g} / \mathrm{L}$ ), its concentration was negligible $(0.20 \mathrm{~g} / \mathrm{L})$ in the electrode solution, while in the concentrate solution $0.59 \mathrm{~g} / \mathrm{L}$ glucose was measured probably due to its diffusion from the feed solution.

\section{Conclusion}

The measurements provided a definite answer to the original question, namely whether ED is a suitable technique for the recovery of itaconic acid. The results of the experiments using model solutions (sodium itaconate on its own as well as a mixture of sodium itaconate and glucose) confirmed that ED is an effective method for the separation of itaconic acid. Based on these results, further experiments are being planned using more complex model solutions, similar to the composition of the fermentation broth. Subsequently, it is our intention to connect the ED module to the fermentation process.

\section{Acknowledgements}

This research was supported by the National Research, Development and Innovation Fund project OTKA K 119940 entitled "Study on the electrochemical effects of bioproduct separation by electrodialysis" and by the financial support of Széchenyi 2020 within project EFOP3.6.1-16-2016-00015. 


\section{REFERENCES}

[1] Baup, S.: Über eine neue Pyrogen- Citronensäure, und über Benennung der Pyrogen Säure überhaupt, Ann. Chim. Phys., 1837 9, 29-38 DOI: 10.1002/jlac.18360190107

[2] Delidovich, I.; Hausoul, P. J.; Deng, L.; Pfutzenreuter, R.; Rose, M.; Palkovits, R.: Alternative monomers based on lignocellulose and their use for polymer production, Chem. Rev., 2016 116(3), 1540-1599 DOI: 10.1021/acs.chemrev.5b00354

[3] Kinoshita, K.: Über die Produktion von Itaconsäure und Mannit durch einen neuen Schimmelpilz, Aspergillus itaconicus, Acta Phytochimica, 1932 5, 271-287

[4] Steiger, M.; Blumhoff, G.; Marzena, L.; Mattanovich, D.; Sauer, M.: Biochemistry of microbial itaconic acid production, Front. Microbiol., 2013 4(23), 1-5 DOI: 10.3389/fmicb.2013.00023

[5] Levinson, W. E.; Kurtzman, C. P.; Kuo, T. M.: Production of itaconic acid by Pseudozyma antarctica NRRL Y-7808 under nitrogen-limited growth conditions, Enzyme Microb. Technol., 200639 (4), 824827 DOI: 10.1016/j.enzmictec.2006.01.005

[6] Kuenz, A.; Krull, S.: Biotechnological production of itaconic acid-things you have to know, Appl. Microbiol. Biotechnol., 2018 102(9), 3901-3914 DOI: 10.1007/s00253-018-8895-7

[7] Heidorn, T.; Camsund, D.; Huang, H.; Lindberg, P.; Oliveria, P.; Stensjo, K.; Lindblad, P.: Synthetic Biology in Cyanobacteria: Engineering and Analyzing Novel Functions, Methods Enzymol., 2011 497, 539-579 DOI: 10.1016/B978-0-12-385075-1.00024-X

[8] Chin, T.; Sano, M.; Takahashi, T.; Ohara, H.; Aso, Y.: Photosynthetic production of itaconic acid in Synechocystis sp. PCC6803, J. Biotechnol., 2015 195, 43-45 DOI: 10.1016/j.jbiotec.2014.12.016

[9] Karaffa, L.; Diaz, R.; Papp, B.; Fekete, E.; Sandor, E.; Kubicek, C. P.: A deficiency of manganese ions in the presence of high sugar concentrations is the critical parameter for achieving high yields of itaconic acid by Aspergillus terreus, Appl. Microbiol. Biotechnol., 2015 99(19), 7937-7944 DOI: 10.1007/s00253-015-6735-6

[10] Magalhăes, A. I.; de Carvalho, J. C.; Ramírez, E. N. M.; Medina, J. D. C.; Soccol, C. R.: Separation of Itaconic Acid from Aqueous Solution onto IonExchange Resins, J. Chem. Eng. Data, 201661 (1), 430-437 DOI: 10.1021/acs.jced.5b00620

[11] Lameloise, M. L.; Matinier, H.; Fargues, C.: Concentration and purification of malate ion from a beverage industry waste water using electrodialysis with homopolar membranes, J. Membr. Sci., 2009 343(1-2), 73-81 DOI: 10.1016/j.memsci.2009.07.013

[12] Molnár, E.; Nemestóthy, N.; Bélafi-Bakó, K.: Galacturonic acid recovery from pectin rich agrowastes by electrodialysis with bipolar membranes, Hung. J. Ind. Chem., 2008 36, 95-99 DOI: 10.1515/186

[13] Stodollick, J.; Femmer, R.; Gloede, M.; Melin, T.; Wessling, M.: Electrodialysis of itaconic acid: A short-cut model quantifying the electrical resistance in the overlimiting current density region, J. Membr. Sci., 2014 453, 275-281 DOI: 10.1016/j.memsci.2013.11.008

[14] Bélafi-Bakó, K.; Molnár, E.; Csanádi, Z.; Nemestóthy, N.: Comparative study on electrodialysis systems for galacturonic acid recovery, Hung. J. Ind. Chem., 2012 40, 65-67 DOI: 10.1515/343

[15] Koutinas, A.; Bélafi-Bakó, K.; Kabiri-Badr, A.; Tóth, A.; Gubicza, L.; Webb, C.: Enzymatic hydrolysis of polysaccharides: Hydrolysis of starch by an enzyme complex from fermentation by Aspergillus awamori, Food Bioprod. Process., 2001 79, 41-45 DOI: $10.1205 / 09603080151123353$ 